\title{
Avaliação e comparação de competências auditivas e cognitivo-linguísticas em crianças de idade escolar
}

\section{Assessment and comparison of auditory and cognitive-linguistic skills in school- age children}

\author{
Inês Martins, Graça S. Carvalho, Cristiane Lima Nunes, Simone Aparecida Capellini \\ CIEC, Universidade do Minho, Portugal
}

\begin{abstract}
Resumo
O desenvolvimento dos sistemas auditivo e cognitivolinguístico ocorrem em simultâneo, assumindo um papel importante na aprendizagem. Surge, assim, a necessidade de investigação dos dois sistemas, através de um estudo quantitativo, com o objetivo de identificar as respostas auditivas e cognitivo-linguísticas mais relacionadas. 150 crianças serão sujeitas à avaliação cognitivo-linguística e 10 à avaliação do Processamento Auditivo. Os pais/professores das 150 crianças preencherão, também, o questionário auditivo para recolha de informações. A análise dos dados dessa avaliação contribuirá para a realização de diagnósticos mais precisos e para a delineação de estratégias de intervenção mais adequadas. Palavras-chave: avaliação, cognição, linguagem, processamento auditivo
\end{abstract}

\begin{abstract}
The development of the auditory and cognitive-linguistic systems occur simultaneously, assuming an important role in learning. Thus, there is a need to investigate the two systems through a quantitative study, with the objective of identifying the most closely related auditory and cognitivelinguistic responses. 150 children will be subject to cognitive-linguistic evaluation and 10 to Auditory Processing evaluation. The parents/teachers of the 150 children will also fill in the auditory questionnaire to collect information. The analysis of the data of this evaluation will contribute to the accomplishment of more accurate diagnoses and to the delineation of more adequate intervention strategies.

Keywords: assessment, auditory processing, cognitivelinguistic responses, school-age children
\end{abstract}

\section{Introdução}

Está descrito na literatura que o desenvolvimento cognitivo-linguístico e o desenvolvimento do sistema auditivo ocorre simultaneamente, pelo que é de se esperar que qualquer alteração em qualquer um destes sistemas, durante os primeiros anos de vida, possa conduzir a dificuldades futuras na aprendizagem, decorrentes das alterações no processamento auditivo dos sons ou nas competências neurocognitivas (Buriti \& Rosa, 2014). De acordo com o estudo realizado por Iliadou, Bamiou, Kaprinis, Kandylis e Kaprinis (2009), a prevalência de Perturbação do Processamento Auditivo em crianças com Perturbação da Aprendizagem Específica é de cerca de $30 \%$ a $50 \%$. Apesar da literatura defender a existência de uma relação entre a cognição e o Processamento Auditivo (PA), não existe uma conformidade de ideias entre os diferentes autores acerca de que processos cognitivos estão envolvidos no PA (Prando, Pawloski, Fachel, Misorelli, \& Fonseca, 2010).

O presente projeto surgiu como uma necessidade de colmatar essa lacuna.

\section{Métodos}

O estudo a realizar será do tipo quantitativo, permitindo a análise de vários parâmetros, como, a dispersão dos dados, a validade interna e perceber de que forma os resultados obtidos e as variáveis se correlacionam (Almeida \& Freire, 2008). Será um estudo descritivo (frequência, média, desvio padrão) e inferencial (teste de Mann-Whitney e correlação de Spearmen). Serão analisadas as variáveis independentes (idade, género e ano escolar) e as variáveis dependentes (competências auditivas e competências cognitivolinguísticas avaliadas).

Dada a relação entre as competências cognitivolinguísticas e auditivas, importantes para a aprendizagem, e dada a elevada prevalência de alterações no processamento auditivo em crianças com dificuldades de aprendizagem, o presente estudo pretende avaliar e comparar as respostas auditivas e cognitivo-linguísticas. Assim, foram definidos os seguintes objetivos:

1- Adaptar e validar o "Protocolo de Avaliação de Habilidades Cognitivo-Linguísticas" brasileiro para português europeu;

2- Traduzir e validar o questionário auditivo "The Auditory Processing Domais Questionnaire", para português europeu;

3- Avaliar as respostas auditivas dos alunos participantes no estudo;

4- Avaliar os processos cognitivo-linguísticos dos alunos participantes no estudo; 
5- Comparar as respostas auditivas dos alunos participantes no estudo com as competências cognitivolinguísticas;

6- Identificar das respostas auditivas e cognitivolinguísticas mais relacionadas.

Tendo em conta os objetivos traçados, foram formuladas as seguintes hipóteses:

1. Existem diferenças nos resultados dos testes auditivos e cognitivo-linguísticos, em relação à variável género;

2. Existem diferenças nos resultados dos testes auditivos e cognitivo-linguísticos, em relação à variável idade;

3. Existem diferenças nos resultados dos testes auditivos e cognitivo-linguísticos, de acordo com o ano escolar que frequentam;

4. Existe relação entre as competências auditivas e cognitivo-linguísticas.

\section{Partcipantes}

A amostra deste estudo será de conveniência e será constituída por um total de 150 crianças, 30 por ano escolar ( $1^{\circ}$ ano ao $5^{\circ}$ ano). Tendo em conta o número da amostra, o teste piloto será realizado com 15 crianças (3 por ano escolar) do mesmo agrupamento de escolas onde irá ser realizado o estudo. As 15 crianças serão suficientes para a realização do estudo piloto, uma vez que correspondem a $10 \%$ do total da amostra, estando de acordo com Canhota (2008).

As 150 crianças serão avaliadas com o Protocolo de Habilidades Cognitivo-Linguísticas, mas apenas 50 (10 por ano escolar), serão avaliadas com os protocolos de avaliação do Processamento Auditivo. A constituição desta amostra tem em conta alguns critérios de inclusão e de exclusão. Para a avaliação do PA necessário que seja realizada uma avaliação prévia, com recurso a um conjunto de procedimentos - visualização do canal auditivo, timpanometria, reflexos acústicos, audiometria tonal e audiometria vocal (Nunes, 2015), para garantir que a criança possui uma audição dentro dos limites da normalidade e posteriormente possa ser incluída no grupo de crianças que será sujeita a essa avaliação. Dada toda a logística implicada na avaliação da acuidade da audição, uma vez que estes testes terão que ser realizados em cabine acústica, nem todas as crianças poderão ser submetidas a esta avaliação, daí serem selecionadas apenas 50 crianças.

\section{Instrumentos}

A avaliação do PA será realizada com recurso a um protocolo de rastreio e a testes comportamentais, realizados com equipamento adequado. No rastreio serão usados os seguintes testes referidos por Nunes (2015): Teste de Localização Sonora (Pereira, 1993); Teste de Memória Sequencial Verbal (Toniolo, 1994); Teste de Memória Sequencial Não-Verbal (Toniolo, 1994). Na avaliação comportamental será usado um protocolo de análise informal de competências auditivas (Nunes, \& Capellini, 2017 - lançamento em 2017), onde serão avaliadas as seguintes competências auditivas: discriminação dos aspetos temporais, resolução temporal, memória auditiva e atenção seletiva.
Para avaliação das competências cognitivo-linguísticas será utilizada a adaptação, para português europeu, do Protocolo de Avaliação de Habilidades CognitivoLinguísticas (Capellini, et al., 2012). Este instrumento de rastreio permite a identificação de crianças com desfasamento em relação à norma, nas diferentes competências cognitivo-linguísticas. Possui uma versão coletiva e uma individual. A versão coletiva inclui 5 subtestes: escrita do alfabeto em sequência; cópia de formas; cálculo matemático; escrita sob ditado de palavras e repetição de números em ordem aleatória. O teste individual inclui 13 subtestes: leitura de palavras; leitura de não palavras; aliteração; rima; repetição de palavras; repetição de não palavras; ritmo; segmentação silábica; nomeação rápida de figuras; nomeação rápida de dígitos; memória visual para formas; discriminação de sons e repetição de números em ordem inversa.

Por fim, será utilizada a tradução do questionário The Auditory Processing Domais Questionnaire (O'Hara, 2015) para português europeu. Este questionário é constituído por 52 comportamentos relacionados com a audição da criança no seu dia-a-dia, não esquecendo as questões da linguagem e da atenção. Em cada questão existem 4 alternativas de resposta à frequência de ocorrência dos comportamentos mencionados (raramente, às vezes, com frequência, quase sempre). Este questionário permitirá recolher informação relevante junto dos pais/professores.

\section{Material e Procedimentos}

Inicialmente serão pedidas as autorizações necessárias aos autores dos instrumentos (Protocolo de Avaliação de Habilidades Cognitivo-Linguísticas e The Auditory Processing Domais Questionnaire) a adaptar e traduzir, respetivamente. Posteriormente proceder-se-á à sua adaptação e validação para o português europeu.

De referir que existe uma versão do questionário The Auditory Processing Domais Questionnaire em português do Brasil (Yokoyama, Dias \& Pereira, 2015), que irá guiar a tradução do instrumento original para o português europeu, como sugerido pelo autor. O Protocolo de Avaliação de Habilidades CognitivoLinguísticas será adaptado linguisticamente do português do Brasil para o de Portugal.

Após a tradução/adaptação linguística, os instrumentos serão comparados com os originais por uma pessoa nativa (retro-tradução) (Beaton, Bombardier, Guillrmin, \& Ferraz, 2000). De seguida o instrumento deverá ser analisado por um comité de peritos e serão feitas as alterações necessárias, se existirem.

Após os instrumentos estarem finalizados será realizado um estudo piloto (pré-teste), para verificar se os mesmos estão corretamente adaptados e se são de fácil compreensão pela população-alvo do estudo ou se, em alternativa, deverão ser feitas algumas alterações (Almeida, \& Freire, 2008; Canhota, 2008).

Antes da recolha de dados é necessário garantir que o estudo esteja salvaguardo nas questões de ética, garantindo o anonimato e a confidencialidade dos dados, pelo que o projeto será submetido à Subcomissão de Ética para as Ciências da Vida e da Saúde (SECVS); 
Comissão Nacional de Proteção de Dados (CNPD) e Direção Geral de Educação.

Após este processo, o diretor do agrupamento de escolas, onde será realizado o estudo, será contactado para explicação do projeto em causa e para posterior pedido de autorização.

Após autorização, do diretor do agrupamento, serão selecionadas as turmas dos diferentes anos escolares que serão alvo do estudo em causa, até a amostra estar completa. Posteriormente, os professores dessas turmas serão contactados para explicação do estudo e para pedido de colaboração no contacto com os pais dos alunos.

Nesta fase é igualmente importante informar os alunos acerca da realização do estudo, explicar em que consiste e esclarecer as dúvidas que poderão surgir. Isto porque, de acordo com Ferreira e Sarmento (2008), é fulcral que as crianças estejam devidamente informadas acerca dos objetivos da investigação, para que possam ter a liberdade de aceitarem ou recusarem a participação no estudo, uma vez que as crianças também devem ser livres de tomar as suas decisões, em relação à sua participação.

Os alunos que aceitarem participar no estudo farão chegar aos pais/encarregados de educação o consentimento informado, para que estes possam dar autorização à participação dos seus educandos no estudo.

Após a recolha do consentimento informado, devidamente assinado, poderá ser feita a recolha de dados.

\section{Resultados/Conclusão}

Estando ainda na fase inicial de implementação do projeto, ainda não existem resultados deste estudo, no entanto, pretende-se provar que existe relação entre as competências cognitivo-linguísticas e as competências auditivas, identificando-se as áreas mais correlacionadas. Estes dados poderão ser úteis na realização de diagnósticos, na delineação de estratégias e métodos de intervenção ajustados às dificuldades de cada criança.

\section{Referências}

Almeida, L. S., \& Freire, T. (2008). Metodologia da investigação em psicologia e educação (5a ed.). Braga: Psiquiíibrios Edições.

Beaton, D. E., Bombardier, C., Guillemin, F., \& Ferraz, M. B. (2000) Guidelines for the process of crosscultural adaptation of self-report measures, 25(24):3186-91. http://dx.doi.org/ 10.1097/00007632200012150-00014

Buriti, A. K. L., \& Rosa, M. R. D. (2014). Percepção auditiva em escolares com dislexia: uma revisão sistemática. Revista Psicopedagogia, 31(94), 82-88. http://dx.doi.org/10.1590/0102-3772e32ne24

Canhota, C. (2008). Qual a importância do estudo piloto? In E. E. Silva (Org.). Investigação passo a passo: perguntas e respostas para investigação clínica (pp. 69-72). Lisboa: APMCG. http://www.arsalgarve.minsaude.pt/wp-content/uploads/2017/01/InvestigacaoPasso-a-Passo.pdf
Capellini, S. A., Smythe, I., \& Silva, C. da. (2012). Protocolo de avalição de habilidades cognitivolinguísticas. Marília: Fundep, Ed.

Ferreira, M., \& Sarmento, M. J. (2008). Subjectividade E Bem-Estar Das Crianças: (In)Visibilidade E Voz, (2), 60-91.

https://www.researchgate.net/publication/277227958 Subjectividade_e_Bem-

Estar_das_Criancas_invisibilidade_e_voz

Iliadou, V., Bamiou, D. E., Kaprinis, S., Kandylis, D., \& Kaprinis, G., (2009). Auditory processing disorders in children suspected of learning disabilities - a need for screening. International journal of pediatric otorhinolaryngoly, 73(7)1029-1034. http://dx.doi.org/10.1016/j.ijporl.2009.04.004

Nunes, C. L. (2015). Processamento auditivo - conhecer, avaliar e intervir. Lisboa: Papa-Letras.

Nunes, C. L., \& Capellini, S. A. (2017). João - O atleta da audição. São Paulo: Ed. Booktoy.

O'Hara, B. (2015). The auditory processing domains questionnaire (APDQ 2015.11). Honolulu, Hawaii.

Prando, M. L., Pawloski, J., Fachel, J. M. G., Misorelli, M. I. L., \& Fonseca, R. P. (2010). Relação entre habilidades de processamento auditivo e funções neuropsicológicas em adolescentes. Revista CEFAC, 12(4), 646-661. ttp://dx.doi.org/10.1590/S151618462010005000027

Yokoyama, C. H., Dias, K. C. \& Pereira, L. D. (2015). The auditory processing domains questionnaire $(A P D Q)$ : versão em português. (tese de mestrado não publicada). Universidade Federal de São Paulo, Brasil. 